\title{
Tijolos vazados como abrigo para adaptação de roedores silvestres em cativeiro
}

\author{
The using of hollow bricks as a shelter for adaptation of \\ wild rodents' colonies in captivity \\ Corlos Graeff-Teixeirn, Cinara T. Garrido, fernanda T. Sontos \\ e luís F.S. Aguiar
}

\begin{abstract}
Resumo Dificuldade para o estabelecimento de colônias de roedores silvestres no laboratório podem impedir realização de estudos experimentais. Descrevemos o emprego de tijolos vazados dentro das gaiolas, com objetivo de proporcionar abrigo e reduzir o estresse dos animais. Isto facilita a limpeza das gaiolas e outros procedimentos, já que os animais permanecem espontaneamente dentro do tijolo, enquanto são transferidos para uma nova gaiola. Este método foi empregado em uma tentativa de adaptação de Oryzomys nigripes em cativeiro. Apesar do transporte por mais de $1500 \mathrm{~km}$, mortalidade foi zero no grupo de 62 roedores e a colônia expandiuse imediatamente. O tijolo vazado é um material barato, facilmente disponível e contribui para a adaptação de roedores silvestres em cativeiro.
\end{abstract}

Palavras-chaves: Rodentia. Oryzomys nigripes. Cativeiro.

Abstract Difficulties for adaptation of wild rodents' colonies in the laboratory may hamper experimental studies. We describe the use of a hollow brick inside cages, to provide shelter and reduce stress of the animals. It facilitates the cleaning of cages, since the animals stay inside the brick while they are transferred to a new cage. This method was applied in a trial for adaptation of Oryzomys nigripes in captivity. Despite transportation for more than $1500 \mathrm{~km}$, mortality was zero in the group of 62 rodents and the colony expanded immediately. A hollow brick is a cheap and widespread available material for improving adaptation of wild rodents to captivity.

Key-words: Rodentia. Oryzomys nigripes. Captivity.

\footnotetext{
Laboratório de Parasitologia, Instituto de Biociências e Curso de Pós-Graduação em Biociências, Pontifícia Universidade Católica do Rio Grande do Sul, Porto Alegre, RS.

Auxílio CNPq 500893/92-6, CAPES (PROBRAL 55/97) e PUCRS.

Endereço para correspondência: Dr. C. Graeff-Teixeira. R. Marquês do Pombal 799/801, 90540-010 Porto Alegre, RS.

Fax: (051) 320-3568

Recebido para publicação em 30/06/97.
} 
No estudo das zoonoses envolvendo roedores silvestres, freqüentemente se faz necessário estabelecer uma colônia em laboratório. Animais repentinamente submetidos a uma restrição dramática de espaço e a um ambiente radicalmente diverso, entram em estresse agudo e, ou morrem, ou deixam de reproduzir-se.

A angiostrongilose abdominal é causada pelo Angiostrongylus costaricensis, que tem como principais hospedeiros, roedores silvestres, tais como Oryzomys nigripes no Sul do Brasil1 e Sigmodon hispidus na América Central4. Diversas cepas de Mus musculus não são hospedeiras bem adaptadas, apresentando infecção com elevada morbi-letalidade5. Por esta razão tornou-se necessário o estabelecimento de uma colônia de O. nigripes, visando especialmente à produção de antígenos e o desenvolvimento de vários estudos sobre esta parasitose.

Para as capturas, armadilhas metálicas, de porta basculante, medindo $26 \times 14 \times 9 \mathrm{~cm}$, foram iscadas com milho e banana e colocadas em locais previamente observados com auxílio de iscas isoladas ("ceva"), quanto ao consumo do milho e presença de fezes com aspecto e tamanho sugestivos de roedores de pequeno porte como o $O$. nigripes: cilindróides e medindo aproximadamente $0,5 \mathrm{~cm}$ de comprimento.

Ao amanhecer, os animais capturados eram imediatamente anestesiados, mediante a colocação da armadilha dentro de um saco plástico contendo algodão embebido em éter etílico. Frente à possibilidade de contaminação por inalação de vírus ou fungos, provenientes das excreções de roedores 2 , recomenda-se que todo este manuseio seja feito com o operador em uso de máscara, óculos de proteção, além de luvas e avental. É necessária atenção total para evitar depressão respiratória do roedor, devendo o saco plástico ser transparente. $O$ ritmo respiratório vai gradativamente se acentuando na primeira fase. Segue-se uma fase em que a frequência diminui e aumenta a amplitude dos movimentos, o que prenuncia a parada respiratória. $O$ roedor deve ser retirado do saco tão logo reduza a mobilidade ativa a ponto de não conseguir prender-se na armadilha ou no saco e ainda na primeira fase de alteração respiratória.

Prendendo o roedor pela pele da região cervical posterior, entre o indicador e polegar, procede-se de imediato a remoção de pulgas e carrapatos. O animal deve ficar sobre uma bacia com água e sabão e procede-se a inspeção da pelagem com uma espátula. Especialmente as pulgas podem desprender-se ou pular e ficarão retidas na superfície da água ensaboada. Os carrapatos costumam ser retirados com auxílio de uma pinça pequena. A região cervical é examinada a seguir, deslocando-se o pinçamento para a região dorsal superior. Como parte do respeito devido à vida animal, deve-se aproveitar todo material recolhido para estudos em cooperação com outros grupos. Com relação aos carrapatos, por exemplo, estudamse riquetsias e espiroquetas 3 .

Identificado o sexo, no máximo dois animais eram colocados em gaiolas de plástico medindo $40 \times 36 \times 16 \mathrm{~cm}$, com tampa metálica, de preferência já formando casais. As gaiolas eram previamente preparadas com um camada grande $(5 \mathrm{~cm})$ de maravalha (serragem), para reduzir a necessidade de troca nas primeiras quatro semanas. Sobre a superfície foi colocada palha retirada do local de captura, embora este procedimento não pareça ter sido decisivo para o sucesso da adaptação, com $O$. nigripes. As gaiolas continham um tijolo vazado, onde os animais imediatamente buscavam abrigo, ao recuperarem-se da anestesia.

Nas primeiras semanas em cativeiro, além da ração comercial para roedores, foi oferecido milho e banana, ambos de grande aceitação.

Para a limpeza das gaiolas, inicialmente se revolve a maravalha para garantir que todos os animais estivessem abrigados dentro do tijolo. Com os orifícios ocluídos por uma cartela de papelão (Figura 1a e 1b), o tijolo contendo os animais pode ser transferido para outra gaiola já limpa, sem necessidade de anestesia. Para o desmame de ninhadas, exame dos animais ou outra necessidade de manuseio, é importante a anestesia, que pode ser facilmente feita pela transferência do tijolo para dentro de um saco plástico com algodão embebido em éter (Figura 2), como já descrito acima. Passados entre 2 e 3 minutos, convém remover o tijolo, fazendo cair os animais, para vigiar e evitar a morte dos animais por depressão anestésica. Para isto, o saco deve ter boa altura e seu orifício mantido bem elevado, para evitar fugas (Figura 2).

Com o emprego do método ora relatado, na instalação da colônia em 1987, nenhum dos 62 animais morreu durante o transporte por via terrestre por cerca de $1500 \mathrm{~km}$, do município de Arvorezinha (RS) até o Rio de Janeiro. Três 
semanas após a chegada ao laboratório foi constatado o nascimento de três ninhadas que sobreviveram e a maioria dos casais produziu ninhadas a cada 30-45 dias, padrão reprodutivo que se manteve por vários anos. Em várias capturas para renovação de matrizes, têm se confirmado a utilidade desta metodologia.
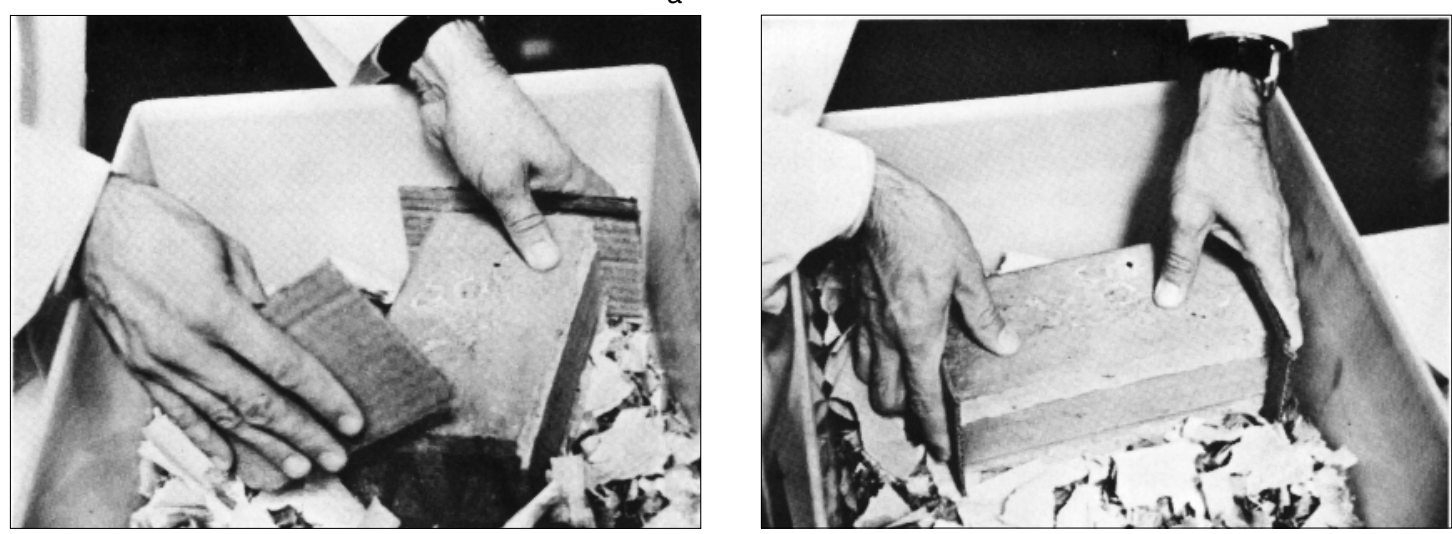

Figura 1 - Demonstração do procedimento de oclusão dos orifícios do tijolo para troca de gaiola ou para anestesia e manuseio dos roedores. Numa situação real, o operador deve usar luvas e máscara.

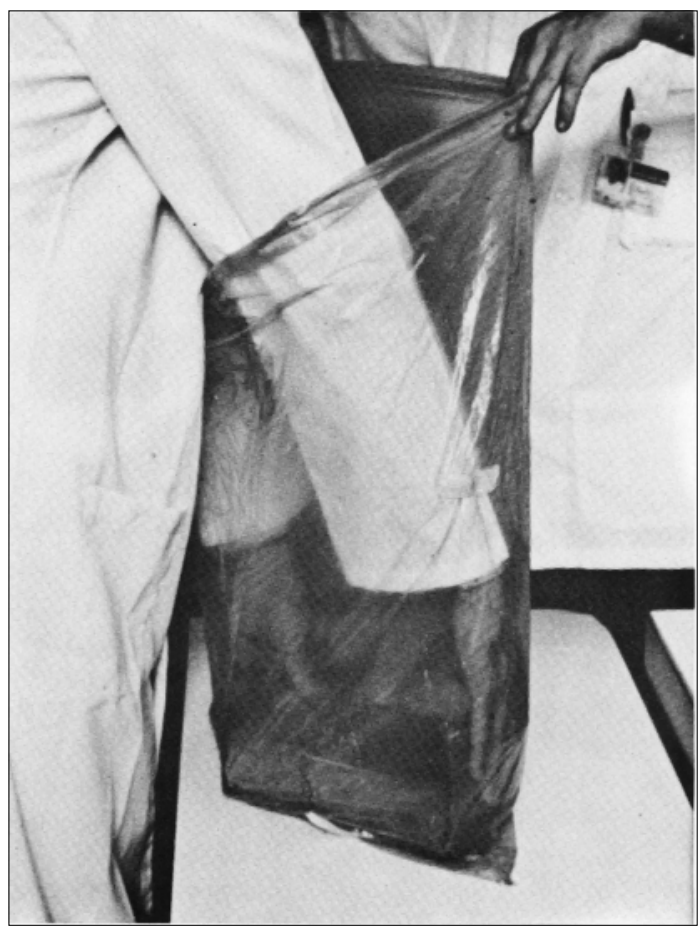

Figura 2 - Demonstração do preparo para anestesia dos animais por inalação com éter etílico, com o tijolo sendo colocado dentro de saco plástico transparente.
É possível que o emprego do tijolo vazado, além de características favoráveis da espécie, tenha uma importância grande na adaptação do O. nigripes ao cativeiro. Os orifícios do tijolo fornecem abrigo, inclusive térmico, especialmente com tijolos de cerâmica. A limpeza da gaiola é muito facilitada, inclusive porque o roedor procura primeiro os orifícios do tijolo antes de fugir para fora da gaiola. Eventualmente, o próprio tijolo poderá ser lavado e autoclavado, sendo uma boa oportunidade por ocasião do desmame. A observação de ninhadas não fica prejudicada pois os ninhos costumam ser arranjados fora do tijolo.

Outro fator talvez importante para adaptação é o uso da anestesia leve a cada manuseio direto dos animais. Não houve, na nossa experiência, evidência de alteração na capacidade reprodutiva pelo uso do éter, de forma judiciosa e espaçada. Com o tempo, tornou-se desnecessário o uso da anestesia, pela docilidade desenvolvida com a adaptação.

Originalmente, tijolos vazados eram utilizados por Eloi Yanez Martin (Serviço de Roedores, FEEMA, Rio de Janeiro) para captura de filhotes de Rattus rattus rattus, no momento do desmame. O uso do tijolo vazado e manipulação sob anestesia constituem metodologia barata, simples e eficaz para o esforço de adaptar roedores silvestres ao cativeiro. 


\section{AGRADECIMENTOS}

A Elias do Nascimento (FIOCRUZ, RJ) e Eva Medeiros (PUCRS,RS) pelo auxílio técnico. Este trabalho foi iniciado no Departamento de Patologia do Instituto Oswaldo Cruz (Dr. HL Lenzi), como parte do trabalho de doutoramento de C. Graeff-Teixeira. Receberam bolsas: CT Garrido (PET-CAPES), FT Santos (BIC FAPERGS e CNPq), LFS Aguiar (Ap CNPq) e C Graeff-Teixeira (PQ IIB CNPq).

\section{REFERÊNCIAS BIBLIOGRÁFICAS}

1. Graeff-Teixeira C, Avila-Pires FD, Machado RCC, Camillo-Coura L, Lenzi HL. Identificação de roedores silvestres como hospedeiros do Angiostrongylus costaricensis no sul do Brasil. Revista do Instituto de Medicina Tropical de São Paulo 32:147-150, 1990.

2. Khan AS, Ksiazek TG, Peters CJ. Hantavirus pulmonary syndrome. Lancet 347: 739-741, 1996.

3. Lemos ERS, Machado RD, Coura JR, Guimarães MAA, Serra-Freire NM, Amorin M, Gazeta GS. Epidemiological aspects of the Brazilian spotted fever: seasonal activity of ticks collected in an endemic area in São Paulo, Brazil. Revista da
Sociedade Brasileira de Medicina Tropical 30:181185, 1997.

4. Morera P. Life history and redescription of Angiostrongylus costaricensis Morera \& Céspedes, 1971. American Journal of Tropical Medicine Hygiene 22: 613-21, 1973.

5. Santos FT, Pinto VM, Graeff-Teixeira C. Evidences against a significant role of Mus musculus as natural host for Angiostrongylus costaricensis. Revista do Instituto de Medicina Tropical de São Paulo 38: 171175, 1996. 